\title{
THE FAITH PRESS
}

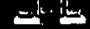

\section{Tufton Street, London S.W.I}

\section{THE PSALMS IN CHRISTIAN WORSHIP}

J. A. LAMB

The Psalms have always filled a very important place in the worship of the Church, but that place has not heretofore been examined in great detail. The present work seeks to repair this omission, and is particularly valuable at a time when the content and structure of worship-forms are being studied in all denominations of the Christian Church. The author, who is Librarian of New College, Edinburgh, is one of Scotland's leading liturgical scholars and is President of the Scottish Church History Society.

21s.

\section{ISAAC WATTS: HYMNS AND SPIRITUAL SONGS}

\section{SELMA BISHOP}

A monumental work, the result of many years' intensive research by a noted American scholar, tracing the changes in the sixteen editions of Watts' famous hymns. This book will not only be of interest to students of Watts. It also reveals the methods and ideas of publishers and printers of his age.

'There is spiritual treasure in plenty to be found ... in this attractive volume on which both editor and publisher are to be congratulated most warmly.'CHURCH TLMES.

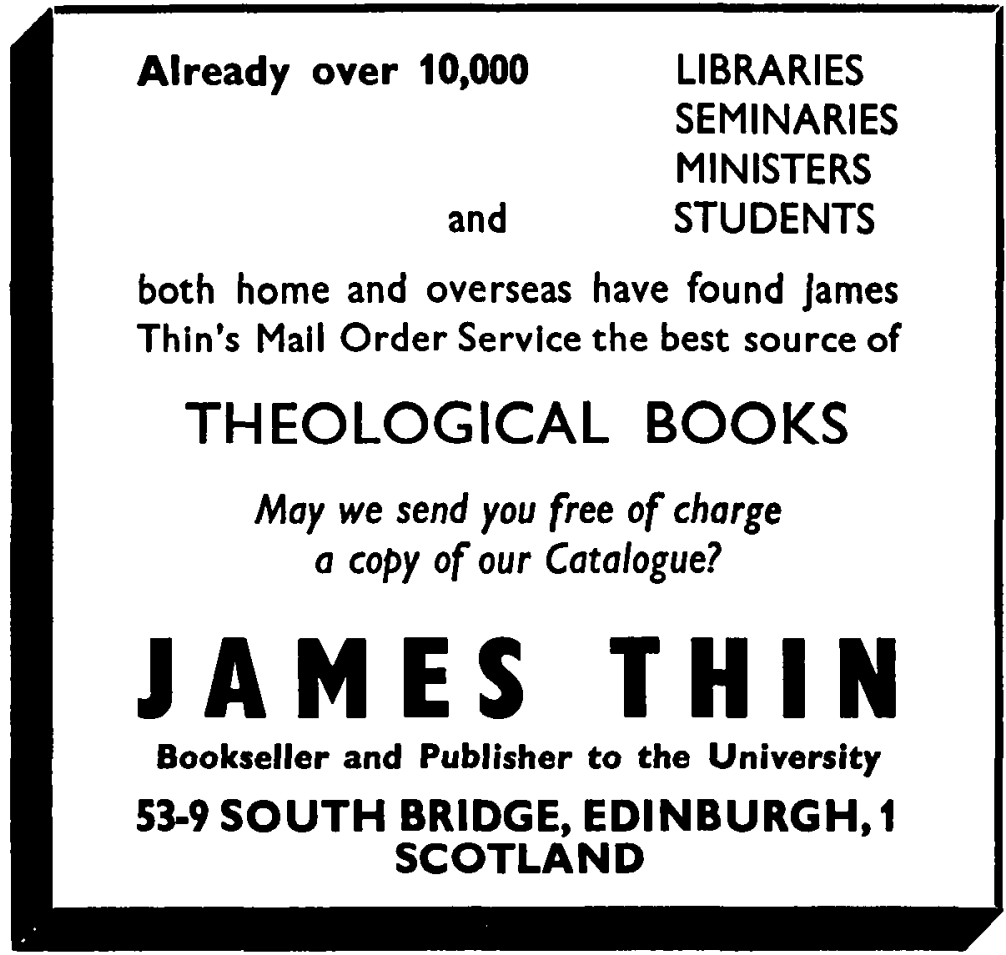

